\section{Poliomyelitis Management in Endemic Areas}

\section{Fahad Saleem}

Department of Pharmacy and Health Sciences, University of Balochistan, Quetta, Pakistan

*Corresponding author: Fahad Saleem, Faculty of Pharmacy and Health Sciences, University of Balochistan, Quetta, Pakistan, Tel: 00923009381144; E-mail: fahaduob@gmail.com

Received date: July 24, 2017; Accepted date: July 26, 2017; Published date: July 31, 2017

Copyright: () 2017 Saleem F. This is an open-access article distributed under the terms of the Creative Commons Attribution License, which permits unrestricted use, distribution, and reproduction in any medium, provided the original author and source are credited.

Citation: Saleem F (2017) Poliomyelitis Management in Endemic Areas. Health Econ Outcome Res 3:e108. DOI: 10.4172/ 2471-268X.1000e108.

\section{Editorial}

The past few years have seen a significant success while dealing with the polio virus and a reduction of $79 \%$ in polio cases was reported worldwide. However, in spite of this success, poliomyelitis still poses an enormous hazard. Within this context, significant positive poliomyelitis cases are reported from Pakistan and Afghanistan [1] one key feature related to poor polio control in endemic areas is the inappropriate handling and storage of the anti-polio vaccine. Evidence from Pakistan revealed that 11,800 vials of anti-polio vaccine worth US $\$ 29,000$ (approximately) were wasted due to poor handling of cold storage facilities, primarily because of unavailability of back up capabilities during electric shortage [2]. Furthermore, Global Alliance for Vaccines and Immunization in their audit report identified mishandling of the vaccine by the programme field staff that was another contributing reason to the failure of the polio campaign in the endemic areas. The vaccinators' neglected WHO criteria of immunization hence wasted $24 \%$ of the expensive vaccine [3]. Moreover, more than 3,000 children aged $>5$ years were vaccinated with expired polio vaccines in South Waziristan Agency, an area that is already pandemic to polio [4]. Rubbing insult to injury, ghost vaccination teams were also identified and $41 \%$ of the polio teams failed to visit the designated areas during polio campaign in Karachi whereas they were fully paid for the very campaign. Equally worst, the supervisors falsely confirmed that the polio campaign was $100 \%$ successful and six cases of polio were later reported from the same city [5]. Last but not the least, supply chain during the polio campaigns is also dubious, as we have observed that in the absence of proper vaccine containers, polio field force in Pakistan sometime utilize plastic thermoses. As the cold chain is to be strictly maintained until the vaccine is administered, using plastic thermoses places a question mark of the stability and efficacy of the vaccine as the field force have to travel for long hours before vaccinating the children.

Therefore, we advocate incessant monitoring, meticulous evaluation and austere audit of the polio campaigns being conducted in the endemic areas. Enough resources are already wasted and this is high time that the endemic countries should provide the complete institutional shoulder to the polio eradication campaign as a strategic priority. Strong commitment, sincerity and positive initiatives are needed from all stakeholders to tackle polio crisis with institutionalization of responsibility and liability as the most important variable in the program evaluation. The world's eyes are set on polio endemic regions and through an earnest collaborative approach, stakeholders have to ensure that this should be the last ditch effort to accomplish the goal of becoming a polio-free nation.

\section{References}

1. Khan MU, Ahmad A, Balkrishnan R (2017) Polio and cross-border management. Lancet Infect Dis 17: 136.

2. Samaa Web Desk (2017) Mishandling of vaccines affects drive against preventable diseases.

3. Pakistan Post Online (2017) $24 \mathrm{pc}$ of costly anti-polio vaccine goes down the drain in Punjab.

4. The Express Tribune (2017) Over 3,000 children given expired polio drops.

5. One Pakistan (2017) $41 \%$ polio teams did not work in field. 